\title{
Last Year Seen
}

National Cancer Institute

\section{Source}

National Cancer Institute. Last Year Seen. NCI Thesaurus. Code C159702.

An indication of the most recent year that a particular event or status was noted. 